\title{
Knowledge, Attitude and Practices Regarding Cataract Surgery among Senile Cataract in Dhaka, Bangladesh
}

Prof. Dr. Md. Sanwar Hossain ${ }^{1 *}$, Dr. Tasnim Khanom ${ }^{2}$, Dr. Mohammad Mazaharul Islam ${ }^{3}$

${ }_{1}^{1}$ Professor, Department of Opthalmology, Dr. Sirajul Islam Medical College and Hospital Ltd, Dhaka, Bangladesh
${ }^{2}$ Assistant Professor, Department of Opthalmology, Dr. Sirajul Islam Medical College and Hospital Ltd, Dhaka, Bangladesh
${ }^{3}$ Resident surgeon(R/S), Department of ophthalmology, Bangabandhu Sheikh Mujib Medical University, Dhaka, Bangladesh

DOI: $10.36347 /$ sasjs.2021.v07i01.002

| Received: 23.12.2020 | Accepted: 08.01.2021 | Published: 11.01.2021

*Corresponding author: Prof. Dr. Md. Sanwar Hossain

Background: Cataract surgery is a procedure to remove the lens of your eye and, in most cases, replace it with an artificial lens. Normally, the lens of your eye is clear. A cataract causes the lens to become cloudy, which eventually affects your vision. Senile cataract is an age-related, vision-impairing disease characterized by gradual progressive clouding and thickening of the lens of the eye. It is the world's leading cause of treatable blindness. Objectives: To know the knowledge, attitude and practices regarding cataract surgery among senile cataract cases. Methods: Cross sectional study; Interview technique. Senile cataract cases were in Dr. Sirajul Islam Medical College and Hospital Ltd, Dhaka, Bangladesh. There were 61 senile cataract cases. Data was entered in MS Excel and Statistical analysis was done using SPSS trial version 22. Results: In Table I: shows age distribution of the patients where most of the patients 26(42.62\%) belong to 60-69 years age group. In Figure I: shows age distribution of the patients where most of the patients $31(50.82 \%)$ belong to Female. In Figure II: shows Distribution of cases according to the diagnosis of the patients where most of the patients $51(100.0 \%)$ had to Cataract. The following table is given below in detail. Conclusion: There is a definite need for exploring the myths regarding cataract and its surgery, through various IEC activities as there is large gap in public's knowledge and understanding of cataract blindness. Much and more emphasis has to be on advance eye surgery so that quality care is provided.

Keywords: Knowledge; Attitude, Practices, Cataract Surgery Senile Cataracts.

Copyright $\odot 2021$ The Author(s): This is an open-access article distributed under the terms of the Creative Commons Attribution 4.0 International License (CC BY-NC 4.0) which permits unrestricted use, distribution, and reproduction in any medium for non-commercial use provided the original author and source are credited.

\section{INTRODUCTION}

Blindness is a disease which has severe economic repercussions and adversely affects the productivity of country. Cataract blindness; in itself; is a public health problem of major proportions in the developing world $[1,2]$. Within the adult population more than 30 years of age, it is estimated that there are approximately 65 million adults' blinds due to cataract in Bangladesh present. It has been assumed that there is a poor access to the causation and treatment of cataract in cataract blinds and when some information on these aspects is available, they don't know where to go for surgical services [3]. Therefore, the present study was carried out to assess the knowledge, attitude and practices regarding cataract and its surgery senile cataract cases were in Dr. Sirajul Islam Medical College and Hospital Ltd, Dhaka, Bangladesh. Regarding knowledge; attitude and practices related to cataract, $1117(90.08 \%)$ cases were aware about "Safed Motia", $123(9.91 \%)$ had not heard about safed motia. Out of
1117 cases; 88 cases $(7.9 \%)$ came to know about this from radio; 148 (13.22\%) from television; 57 (5.08\%) from newspapers and $824(73.79 \%)$ from other agency like peer groups/relatives. $534(47.82 \%)$ cases responded that cataract commonly affects after 60 years of age, while 301 (26.94\%) cases responded about 4060 years of age group rest $282(25.24 \%)$ did not know the exact age group affected. Out of 1117 cases; 240 $(21.45 \%)$ cases related the cataract to religious reasons; $643(57.58 \%)$ linked it to old age while $367(32.9 \%)$ with socio-environmental factors rest $47(4.19 \%)$ could not cite any specific reasons. Regarding sources of treatment; $62(5.56 \%)$ cases were ready to take the treatment from quacks. Majority i.e. $638 \quad(57.1 \%)$ preferred the treatment from allopathic doctor and 405 $(36.28 \%)$ thought it better to try for alternative medicinal system. Concerning treatment; 284 (25.4\%) cases believed that cure can be instilling medicines, while $814(65.64 \%)$ responded for surgery, rest 19 $(1.7 \%)$ were not sure about treatment. 982 cases $(87.9 \%)$ opined that facility for surgery might be 
available in nearby government hospitals. 608 (54.43\%) cases responded for private doctors. 819 cases $(73.3 \%)$ responded regarding camp surgery. Regarding reasons for not getting cataract surgery by $111(9.92 \%)$ cases; 46 cases $(41.46 \%)$ cited the economic constraint as the main reason. As far as surgery was concerned; majority i.e. $714(70.64 \%)$ cases wanted to get it operated upon till able to see nothing. $212(20 \%)$ cases were ready for surgery at the advice of doctor. As far as knowledge regarding type of cataract surgery was concerned.

\section{MATERIAL AND METHODS}

A population of 61 persons above 40 years of age; was considered as a "cluster unit". The study design used for this study is cross sectional study and the study period is from May 2019 to April 2020. The study was done Dr. Sirajul Islam Medical College and Hospital Ltd, Dhaka, Bangladesh and done by the Department of Ophthalmology. The sampling technique used is systematic random sampling. Inclusion criteria: Patients with cataract coming to the ophthalmology OPD. Exclusion criteria: Patients not willing for study and patients with causes of blindness other than cataract. Data was entered in MS Excel and Statistical analysis was done using SPSS trial version 22. Institutional Ethical committee clearance obtained.

\section{RESULTS}

The total study population was 61 Patients aged 40 years to $>69$ years, The total study population was 61 Patients aged 40 years to $>69$ years, $2(3.28 \%)$ were 40 years to 49 years, $15(24.6 \%)$ were 50 years to 59 years, $26(42.62 \%)$ were 60 years to 69 years and $18(29.50 \%)$ ware $>69$ years. Table I demonstrated the Distribution of study patients according to age. Figure I demonstrated the Distribution of study patients according to sex, 31(50.82\%) were Female, and $30(49.18 \%)$ ware Male. The study population $51(50.82 \%)$ had cataract, $45 \quad(88.24 \%)$ had Pseudophakia and 6(49.18\%) ware posterior capsule opacification. Figure II demonstrated the Distribution of cases to the diagnosis.

Table-I: Distribution of study patients by age (n -61)

\begin{tabular}{|l|l|l|}
\hline Age group & $\mathbf{N = 6 1}$ & $\mathbf{\%}$ \\
\hline 40 to 49 years & 2 & 3.28 \\
\hline 50 to 59 years & 15 & 24.6 \\
\hline 60 to 69 years & 26 & 42.62 \\
\hline$>69$ years & 18 & 29.50 \\
\hline Total & 61 & 100.0 \\
\hline
\end{tabular}

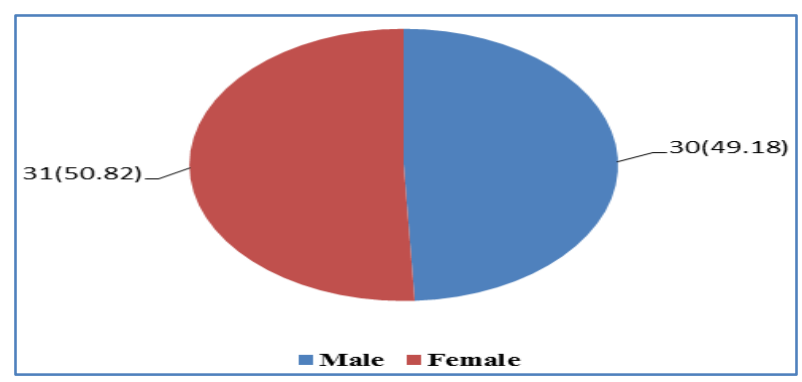

Fig-I: Distribution of study patients by Sex (n -61)

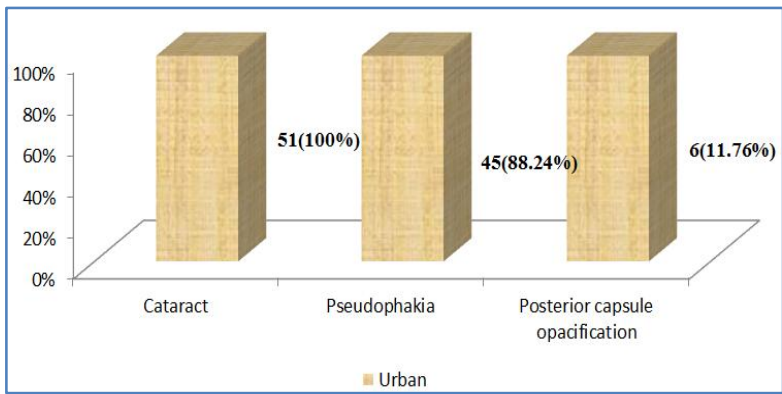

Fig-II: Distribution of cases according to the diagnosis

\section{DISCUSSION}

It becomes difficult to sit back and relax when million Bangladeshi are blinded by cataract annually and curable blindness backlog is increasing day by day. There is always a definite need for better quality information, education and communication on eye care to reach the public so that existing facilities can be availed. People may be unaware of the possibilities to get their sight restored through operation. Thus, to explore the myths and attitude of the people towards cataract blindness; this study was conducted. Majority of cases $(41.93 \%)$ interviewed; in our study; were in age group of 60-69 years similar to those reported by Soundarssanane et al. [5] (40.37\%), Chatterjee et al. [6] $(43.3 \%)$. In Haryana; literacy rate is $55.33 \%$ [7]. $43.55 \%$ cases in our study were literate. Less number of literates in the study may be because of characteristic of rural population. Bilateral cataracts cases were higher in rural areas $(67.46 \%)$ in comparison to urban areas (46.83\%). Similarly, this may be due to less awareness and less facilities for surgery in rural areas in comparison to urban areas. Ignorance regarding disease may be a factor for the existing blindness. $90.08 \%$ cases were aware about safed motia similar to studies of Brilliant and Brilliant [8] (93.5\%). Majority of cases $(73.79 \%)$ in our study got the knowledge regarding safed motia from peer group/relatives. While Das and Venkataswami9 reported that $76.46 \%$ of people came to know about cataract surgery from other agencies. Reason may be different I.E.C. activities in different areas. Poor knowledge regarding cataract in community is reflected from the facts that only $47.8 \%$ opined that above 60 years of patients are affected by cataract. Only $4.19 \%$ cases couldn't cite any specific reasons for cataract. Brilliant and Brilliant 8 found majority of the cases citing unspecific causes. This shows that the awareness campaigns needs to be sped up so that public is given right information. $638(57.1 \%)$ cases preferred to take the treatment from allopathic doctors while 284 (25.4\%) opined that medicine instilled can cure it which shows that still adequate and right knowledge regarding treatment is not there in the population which may be a reason for untreated cataract blindness. Though majority i.e. $65.64 \%$ opined that ultimately some form of surgery is required to use it. So campaigns have to be there to overcome these beliefs regarding cataract. Majority; 982 (87.9\%) cases; though not sure; had 
belief that government hospitals are providing surgical facilities. At the same time, a good number 819 (73.3\%) responded favourably regarding camp surgery. It may be because camps are being organised regularly in most of the areas and in some areas; knowingly these are organised in government hospitals. Economic constraints and poor/no knowledge were the main reasons for not getting cataract surgery in $41.46 \%$ and $31.7 \%$ cases respectively; out of 111 cases who could not avail services, similar to findings of Brilliant and Brilliant8 (29\%). For $11.38 \%$ cases, no helper was available. Other reasons like too old to get surgery done or lack of transportation were also cited. To remove all these barriers; services has to be provided at the door step or within the reach of the people: $20 \%$ cases were ready to get the cataract surgery done at the advice of doctor while $70.64 \%$ cases wanted it only at a time when nothing is visible: The same has been confirmed by Limburg $\mathrm{H}$ et al. [10]. It may be a factor for increasing backlog and unwillingness or misbelief may be a hindrance to total cure of blindness.

\section{CONCLUSION\& RECOMMENDATIONS}

One of interesting finding was that 726 $(72.36 \%)$ cases preferred cataract surgery without IOL and $180(27.64 \%)$ preferred IOL which are contrary to findings of Gupta et al. [11, 12] regarding data on surgeries performed. The reason may be that in our study, number of cases from rural areas was more where IOL surgery has still not gained confidence of patients. There is also a direct link between acceptance of IOL surgery with literacy and literacy rate is less in rural areas. Thus to make cataract surgery more acceptable; affordable and within the reach of the patients, a definite propaganda has to be there in masses. People are to be told more and more about its benefits and only then ever increasing cataract blindness can be cured. Communication packages need to be devised to educate especially the rural population on the importance of curable blindness and prompt advanced surgery.

\section{REFERENCES}

1. Ellwein LB, Kupfer C. Strategic issues in cataract blindness prevention in developing countries. Bull WHO. 1995; 73(3): 681-90.

2. Bourne RR, Dineen BP, Ali SM, Huq DM, Johnson $\mathrm{Gj}$. Outcomes of cataract surgery in Bangladesh: results from a population based nationwide survey. Br J Ophthalmol. 2003;87(7):813-819.

3. Thylefors B, Negrel AD, Pararajasegaram R, Dadzie KY. Global data on blindness. Comm Eye Health. 1996; 9 (17): 1-8.

4. Gupta SK, Murthy GV, Angra SK. Social implications of cataract related blindness in rural India. Aging-Indian Perspective and Global Scenario. New Delhi: All India Institute of Medical Sciences. 1996:126-9.

5. Minassian DC, Mehra V. 3.8 million blinded by cataract each year: projections from the first epidemiological study of incidence of cataract blindness in India. British journal of ophthalmology. 1990 Jun 1;74(6):341-3.

6. Soundarssanane MB, Bansal RD, Narayan KA. An epidemiological study of cataract in a rural area of Pondicherry. Ind J Med Sci. 1986; 40: 273-7.

7. Chatterjee A, Milton RC, Thyle Sydney. Prevalence and aetiology of cataract in Punjab. Br J Ophthal. 1982; 66: 35-42.

8. Registrar General and Census Commissioner of India. Census of India 1991, Provisional Population Totals, page $1 \& 2$.

9. Brilliant GE, Brilliant LB. Using social epidemiology to understand who stays blind and who gets operated for cataract in rural setting. Soc Sci Med. 1985; 21: 553-8.

10. Das T, Venkataswamy. Social, economic and behavioural determinants of utilisation of cataract surgery in Mobile Eye Camps. Ind J Ophthalmol. 1985; 33: 273-6.

11. Limburg H, Vaidyanathan K, Pampattiwar KN. Cataract blindness on the rise? Results of a door-todoor examination in Mohadi. Ind $\mathbf{J}$ Ophthalmol. 1996; 44(4): 241-4.

12. Gupta AK, Ellwein LB. The pattern of cataract surgery in India: 1992. Ind J Ophthalmol. 1995; 43: $3-8$. 